\title{
Mediolateral episiotomy and risk of obstetric anal sphincter injuries and adverse neonatal outcomes during operative vaginal delivery in nulliparous women: a propensity-score analysis
}

Thomas Desplanches ${ }^{1,2^{*}}$, Laetitia Marchand-Martin², Emilie-Denise Szczepanski ${ }^{1}$, Marie Ruillier ${ }^{1}$, Jonathan Cottenet ${ }^{3,4,5}$, Denis Semama ${ }^{6}$, Emmanuel Simon ${ }^{1}$, Catherine Quantin ${ }^{3,4,5,7}$ and Paul Sagot ${ }^{1}$

\begin{abstract}
Background: The potential protective effect of mediolateral episiotomy for obstetrical anal sphincter injuries (OASIs) remains controversial during operative vaginal delivery because of the difficulties to take into account the risk factors and clinical conditions at delivery; in addition, little is known about the potential benefits of mediolateral episiotomy on neonatal outcomes.

The objectives were to investigate the associations between mediolateral episiotomy and both OASIs and neonatal outcomes, using propensity scores.

Methods: We performed a retrospective population-based observational study from a perinatal registry that includes all births in a French region between 2010 and 2017. All nulliparous women with singleton pregnancy delivering by operative vaginal deliveries at 37 weeks gestational age or later were included. Inverse-probability-of-treatment weighting with propensity scores was used to minimize indication bias. OASIs was defined as third and fourth-degree tears according to Royal College of Obstetricians and Gynecologists. Two neonatal outcomes were studied: condition at birth (5-min Apgar score less than 7 and/or umbilical artery pH less than 7.10), and admission to neonatal intensive care unit.
\end{abstract}

Results: The study population consisted of 7589 women; 2880 (38.0\%) received mediolateral episiotomy. After applying propensity scores, episiotomy was associated with a lower rate of OASIs in forceps/spatula delivery (2.3 vs 6.8\%, Risk Ratio (RR) 0.38, 95\% Confidence Interval (Cl) 0.28-0.52) and in vacuum delivery (1.3 vs 3.4\%, RR 0.27, 95\% Cl $0.20-0.38$ ) as compared with no episiotomy. Mediolateral episiotomy was associated with better condition at birth in case of forceps/spatula delivery (4.5 vs 8.8\%, RR $0.56,95 \%$ Cl 0.39-0.81). In cases of fetal distress (40.7\%), mediolateral episiotomy was associated with better condition of infant at birth in women who delivered by forceps/spatula (4.2 vs $13.5 \%$, RR 0.52 , 95\% Cl 0.31-0.89). No association was found with neonatal unit admission (RR 0.93, 95\% Cl 0.50-1.74).

*Correspondence: thomas.desplanches@inserm.fr

2 Obstetrical, Perinatal and Pediatric Epidemiology Team (EPOPé), Center

of Research in Epidemiology and Statistics (U1153), Team EPOPé U1153,

Université de Paris, Inserm, Paris, France

Full list of author information is available at the end of the article

(C) The Author(s) 2022. Open Access This article is licensed under a Creative Commons Attribution 4.0 International License, which permits use, sharing, adaptation, distribution and reproduction in any medium or format, as long as you give appropriate credit to the original author(s) and the source, provide a link to the Creative Commons licence, and indicate if changes were made. The images or other third party material in this article are included in the article's Creative Commons licence, unless indicated otherwise in a credit line to the material. If material is not included in the article's Creative Commons licence and your intended use is not permitted by statutory regulation or exceeds the permitted use, you will need to obtain permission directly from the copyright holder. To view a copy of this licence, visit http://creativecommons.org/licenses/by/4.0/. The Creative Commons Public Domain Dedication waiver (http://creativeco mmons.org/publicdomain/zero/1.0/) applies to the data made available in this article, unless otherwise stated in a credit line to the data. 
Conclusions: Use of mediolateral episiotomy was associated with a lower rate of OASIs during operative vaginal delivery, and in infants it was associated with better condition at birth following forceps/spatula delivery.

Keywords: Operative vaginal deliveries, Episiotomy, Obstetric anal sphincter injuries, Adverse neonatal outcomes, Propensity score

\section{Background}

Obstetric anal sphincter injuries (OASIs) are a rare but severe complication of vaginal delivery, with a prevalence between 0.25 and $6.0 \%$ [1]. These injuries have a major impact on women's short-term and long-term health and well-being [2].

In 2016, 12.4\% of deliveries in France were operative vaginal deliveries (OVD) [3], which is one of the most significant risk factors for OASIs [4]. OVD is more frequently performed in nulliparous than in multiparous women, and nulliparity is associated with the risk of OASIs [4]. The combination of these two risk factors contributes considerably to OASIs rates [5].

The potential protective effect of mediolateral episiotomy to prevent OASIs during OVD remains controversial, and several international guidelines recommend that mediolateral episiotomy "should be considered" [6-8]. In a pilot study for a planned randomized controlled trial that has addressed this issue [9], the authors concluded that a policy of routine episiotomy is not better or worse than a restrictive policy. However, the sample size was small, limiting the conclusions of this study. The results of observational studies are contradictory [10-20], and their conclusions may be limited owing to insufficient consideration of the confounding bias by indication. The implementation of a very restrictive episiotomy policy could even be associated with an increase in OASIs incidence during forceps delivery [21]. The major problem when evaluating OASIs is that maternal, fetal and medical characteristics are different in the episiotomy and no episiotomy groups. Previous studies have mostly used traditional covariate adjustment in regression models for risk adjustment. However, when there are great differences in important prognostic characteristics, adjusting for these differences with conventional multivariable techniques may not adequately balance the groups [22]. A propensity score (PSs) has been shown to effectively balance measured covariates between two groups in comparative observational studies [23].

In addition to the maternal complications associated with OVD, neonatal complications such as neonatal hypoxia may occur at birth [24]. Very few studies reported data on the association between episiotomy and adverse neonatal outcomes during OVD [9, 13, 14]. They found no association but the number of adverse neonatal outcomes was low, thus limiting the power of their analysis. The indication of episiotomy for fetal distress was regularly reported by obstetricians in several studies $[25,26]$. It therefore seems relevant to study whether there is a difference in neonatal health status depending on whether or not a mediolateral episiotomy is performed.

Our objective was to assess the association between mediolateral episiotomy and both OASIs and adverse neonatal outcomes. The analysis in this study is focused on controlling for indication bias: we restricted our analysis to nulliparous women with singleton pregnancy delivering by OVD at term, and we used propensity scores to control for residual confounding by indication.

\section{Methods}

\section{Study design and population study}

This retrospective observational study was conducted in Burgundy, France, between January 2010 and December 2017. Over this 8-year period, 12 maternities managed approximately 17,000 births per year. Levels of care are based on a three-tiered system defined by national regulation. These facilities are gathered in the hierarchical Burgundy perinatal network (BPN), which was accredited by the regional health authorities in 2000 .

All deliveries and terminations of pregnancies that occur within the BPN at or after 22 completed weeks of gestation and/or with a birth weight $>500 \mathrm{~g}$ have been systematically recorded in an anonymous database used to regularly assess the medical practices within the network. Maternal and neonatal medical data are prospectively recorded from the mandatory discharge abstracts for each hospitalized patient (used to determine the activity-based funding of French hospitals). Twenty additional specific perinatal characteristics, eleven for each mother and nine for each newborn, were also prospectively recorded. In accordance with European and French law, patient data have to be rendered anonymous in each maternity unit before being sent to the evaluation unit for data validation and mother/child linkage. The anonymization methods routinely used for BPN data were developed by our research team. ANONYMAT Software are also used in national applications [27].

In the current study, we restricted the analyses to nulliparous women who delivered a singleton live infant in cephalic presentation by an OVD at 37 weeks gestational age or later in 9 of the 12 maternity units in the region 
(five level-I maternity units, three level-II maternity units and one level-III maternity unit (university hospital)).

We excluded 3 hospitals from the analyses because data on parity, induction of labor, and Apgar score were not collected during the entire period in 2 hospitals, and the last hospital was closed during the study period.

\section{Outcomes and exposition measures}

To classify OASIs, we used the Royal College of Obstetricians and Gynecologists classification [7], which is most widely used in the international literature. Only thirddegree (defined as injuries of external and/or internal anal sphincter) and fourth-degree tears (defined as injuries of anal sphincter complex and anorectal mucosa) were taken into account and pooled for the analyses. OASIs was diagnosed by an obstetrician with a clinical examination (vaginal and rectal examination) of the perineum just after operative vaginal delivery. OASIs was identified in our database using the International Classification of Diseases 10th Revision (ICD-10 codes O702 - third degree perineal laceration during pregnancy and O703 - fourth-degree perineal laceration during pregnancy) and/ or the French Common Classification of Medical Procedures (CCAM codes JMCA001- Immediate suture of obstetrical tear of the perineum with lesion of the rectum, and JMCA003 - Immediate suture of obstetrical tear of the perineum with lesion of the external sphincter muscle of the anus). The first code is related to the diagnosis, and the second code corresponds to the surgical procedure.

Two adverse neonatal outcomes were studied: condition at birth, including low Apgar score (5-min Apgar score $<7$ ) [28] and/or low arterial blood gases (umbilical artery $\mathrm{pH}<7.10)[29,30]$; and admission to neonatal intensive care unit (NICU). Adverse neonatal outcomes were studied in the 2013-2017 period because umbilical artery $\mathrm{pH}$ values were systematically recorded from 2013 in the level II and III maternity units.

Mediolateral episiotomy was identified with the French Common Classification of Medical Procedures (code JMPA006).

\section{Statistical analysis}

Maternal characteristics were compared in women who had episiotomy and women who did not, using $\mathrm{Chi}^{2}$ tests. The changes over time in the mediolateral episiotomy rate, the OVD rate and the OASIs rate were described using the Cochran-Armitage test.

To control confounding factors that might influence the use of episiotomy and the occurrence of OASIs, we used a PS approach. A woman's PS was defined as the probability that she would have an episiotomy intervention based on her individual covariates [31]. The first step was to estimate a propensity score for all women using a logistic regression model with episiotomy as the dependent variable in relation to the following baseline maternal and obstetrical characteristics: induction of labor, prolonged pregnancy defined as more than $41^{+0}$ weeks of gestation, epidural analgesia, fetal distress during labor [32], occiput posterior position, mode of delivery (forceps and spatula delivery were grouped, and vacuum delivery), birth weight as a proxy of prenatal suspicion of large for gestational age, year of delivery, and level of maternity unit. Variables included in the PSs model were based on the literature [4].

Then, the inverse probability of treatment weighting (IPTW) based on estimated PSs was used to obtain a pseudo population in which treatment assignment is independent of measured baseline covariates [22]. The comparability of groups was verified by calculating standardized differences in the weighted samples. A standardized difference below $10 \%$ is considered an acceptable imbalance between groups [22].

We finally estimated the association between mediolateral episiotomy and OASIs using mixed log-poisson regression models, obtaining risk ratios (RRs) and 95\% confidence intervals (CIs). We used multilevel modelling to take into account the hierarchical structure of the data (women within maternity units) and the nonindependence of observations within maternity units.

We also investigated the associations between mediolateral episiotomy and adverse neonatal outcomes with similar methodologies. PSs were estimated using a logistic regression model that included all possible confounders likely to have affected neonatal outcomes, including maternal age, BMI, smoking, gestational diabetes, hypertension disorders in pregnancy (defined as gestational hypertension, and pre-eclampsia associated or not with complications such as HELLP syndrome, eclampsia and placental abruption), induction of labor, prolonged pregnancy, epidural analgesia, fetal distress, occiput posterior position, mode of delivery, small for gestational age as a proxy of prenatal suspicion of small for gestational age (SGA, defined as $<10$ th percentile for gestational age) [33], year of delivery and level of maternity unit. We investigated the association of mediolateral episiotomy with two indicators of infant condition at birth: 5-min Apgar scores less than 7 and/ or umbilical artery $\mathrm{pH}$ less than 7.10, and admission to NICU.

Fetal distress during labor [32] is one the most frequently reported clinical indications for episiotomy use [25] and is known to be associated with infant condition at birth. We therefore performed stratified analyses according to fetal distress status. We recalculated PSs, and a second set of analyses compared the association 
between mediolateral episiotomy and condition at birth according to fetal distress status.

All of our analyses were stratified by the type of OVD (forceps/spatula or vacuum). Deliveries by spatula, an instrument for propulsion and direction, were grouped with forceps delivery [34].

Deliveries with sequential use of instruments were included in the forceps/spatula group, because they were not frequent and forceps are often used after a failed attempt at ventouse-assisted delivery.

Statistical significance was set with a two-tailed test at $p<0.05$. All analyses were done with SAS v9.4 software.

\section{Missing data}

Most of the variables used in this study had an exhaustiveness of $100 \%$ or less than $5 \%$ missing data, so the association between mediolateral episiotomy and OASIs was investigated on complete cases. However, the percentage of missing data for adverse neonatal outcomes was $9.4 \%$. Analyses were first done on complete cases, and we then ran our models using multiple imputations (chained equations with a logistic regression imputation model for missing binary data and a multinomial imputation model for missing categorical data) [35]. Missing data were imputed by chained equations using the SAS "MI" procedure. Imputation model variables included maternal and neonatal characteristics: year of delivery, maternal age, smoking during pregnancy, body mass index, gestational diabetes, hypertension disorders in pregnancy, induction of labor, prolonged pregnancy, epidural analgesia, fetal distress, occiput posterior position, mode of delivery, birth weight, level of maternity unit, mediolateral episiotomy and outcomes. We generated 50 independent imputed datasets. A PSs was estimated for each of the generated datasets, and the results were pooled for a final analysis according to Rubin's rules [35].

\section{Results}

We included 7589 nulliparous women who had an OVD of a single infant at term during the study period (Fig. 1). Vacuum delivery was more frequent than forceps/spatula delivery, respectively 64.3 and $33.7 \%$. The proportion of vacuum delivery increased from 2010 to 2017 (Additional file: Table 1). The proportion of mediolateral episiotomy was $38.0 \%$ (2880). From 2010 to 2017, mediolateral episiotomy practices significantly decreased from 48.0 to 23.6\% (Cochran-Armitage Test $P<0.001$ ). The OASIs rate of $3.4 \%$ remained stable from 2010 to 2017 (Additional file: Table 1).

Maternal, labor and hospital characteristics for women with and without mediolateral episiotomy are presented in Table 1. Most of these characteristics differed significantly between the two groups. Episiotomy was more frequent in women requiring forceps/spatula extraction than vacuum extraction $(53.1 \%(1433 / 2698)$ vs $29.3 \%$ (1421/4853), $P<0.01$ ) (Table 1).

PSs were calculated and covariates were balanced in the two groups (standardized differences in the weighted samples were less than 10\%).

Mediolateral episiotomy was associated with lower rates of OASIs in forceps/spatula delivery ( 2.3 vs $6.8 \%$, Risk Ratio 0.38, 95\% Confidence Interval (CI) 0.28-0.52) and in vacuum delivery ( 1.3 vs $3.4 \%$, RR $0.27,95 \% \mathrm{CI}$ 0.20-0.38) (Table 2).

For neonatal outcomes, a total of 3586 infants were included (Fig. 1). Mediolateral episiotomy was associated with better condition at birth ( $\mathrm{pH}$ umbilical artery $<7.10$ or 5-min Apgar score $<7$ ) in women who delivered by forceps/spatula ( 4.5 vs $8.8 \%$, RR 0.56 , 95\% CI $0.39-0.81$ ) (Table 3$)$. This result was confirmed after multiple imputation (RR 0.63, 95\% CI 0.40-0.99) (data not shown).

In cases of fetal distress (40.7\%), mediolateral episiotomy was again associated with better infant condition at birth in women who delivered by forceps/spatula (4.2 vs $13.5 \%$, RR 0.52, 95\% CI 0.31-0.89) (Table 4).

We found no association between episiotomy and admission to NICU (Additional file: Table 2). Among the 83 infants admitted, 6 died.

\section{Discussion}

Using a PS method, our study shows that whatever the type of OVD, mediolateral episiotomy was associated with a significantly lower rate of OASIs in nulliparous women with singleton pregnancy and OVD at term. Additionally, mediolateral episiotomy was associated with better infant condition at birth in case of forceps/spatula delivery, and in particular in cases of fetal distress.

In the present study, we used a rigorous IPTW method with PSs to minimize indication biases. The best current practices for the use of IPTW were followed [22]. The main confounding factors were included in our analysis. In addition, a mixed-model approach was used to take into consideration the clustering of births within hospitals. Our population was selected from a large regional registry which collected data prospectively and provided 8 years of reliable and recent data from level I, II and III maternity units belonging to the same perinatal network. The characteristics of our regional population, and the medical practices reported are similar to those observed in the France in 2016 [3].

This study has several limitations. First, this study was a retrospective observational study. Because randomization was impossible, we adjusted covariates available from the BPN database using IPWT methods. Second, additional unmeasured confounding factors might have 


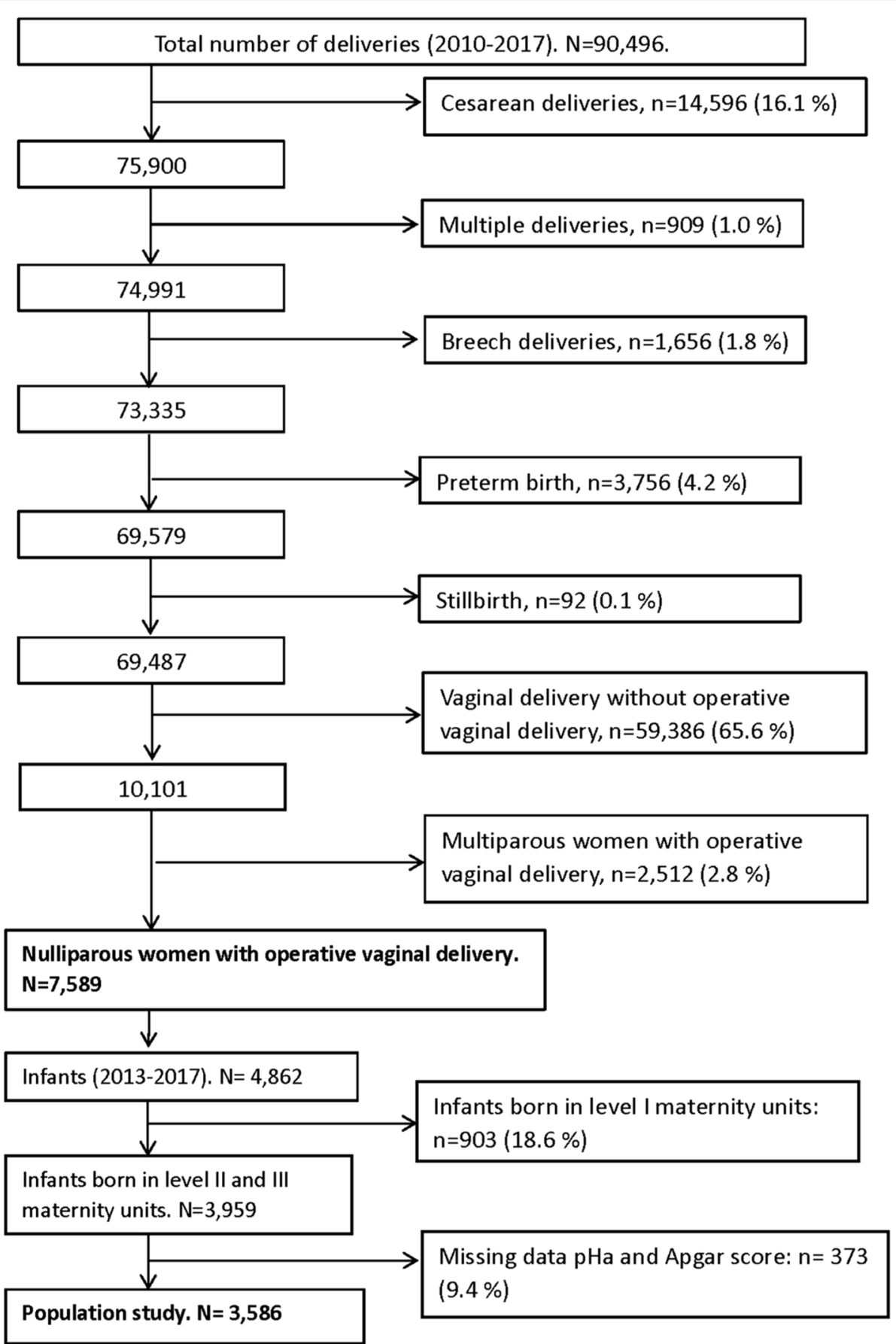

Fig. 1 flow chart

affected the outcomes. We had no information regarding ethnicity as the collection of this information is not allowed in France. However, Asian women, a group at high risk of OASIs [4], make up a very small proportion of women who deliver in France. For instance, French census data suggests that only $1.7 \%$ of women who delivered in France in 2018 were born in Asia [36]. Data relative to the duration of second stage, operator experience and other interventions for perineal prevention such manual control of the expulsion and perineal support were not recorded. These practices are known to reduce the risk of perineal sphincter tears [37] and are 
Table 1 Maternal, labor, neonatal and hospital characteristics without and with mediolateral episiotomy in nulliparous women with singleton pregnancy delivering by operative vaginal delivery at term

\begin{tabular}{|c|c|c|c|}
\hline Characteristics, n (\%) & $\begin{array}{l}\text { Mediolateral episiotomy } \\
N=2880\end{array}$ & $\begin{array}{l}\text { No mediolateral episiotomy } \\
N=4709\end{array}$ & $P$ Value ${ }^{*}$ \\
\hline \multicolumn{4}{|l|}{ Maternal characteristics } \\
\hline Maternal age, years & & & 0.08 \\
\hline$<25$ & $933(32.4)$ & $1414(30.0)$ & \\
\hline $25-34$ & $1753(60.9)$ & $2954(62.7)$ & \\
\hline$>35$ & $194(6.7)$ & $341(7.3)$ & \\
\hline Body mass index, $\mathrm{kg} / \mathrm{m}^{2}$ & & & 0.01 \\
\hline$<18.5$ & $183(7.4)$ & $314(7.2)$ & \\
\hline $18.5-24.9$ & $1597(65.4)$ & $2774(63.7)$ & \\
\hline $25-29.9$ & $456(18.7)$ & $812(18.7)$ & \\
\hline$\geq 30$ & $207(8.5)$ & $448(10.3)$ & \\
\hline Missing data & 437 & 361 & \\
\hline Smoking during pregnancy & $374(13.0)$ & $714(15.1)$ & 0.01 \\
\hline Gestational diabetes & $225(7.8)$ & $478(10.1)$ & 0.01 \\
\hline Hypertension disorder of pregnancy & $105(3.6)$ & $190(4.0)$ & 0.39 \\
\hline \multicolumn{4}{|l|}{ Labor, neonatal characteristics } \\
\hline Induction of labor & $581(20.2)$ & $1010(21.5)$ & 0.18 \\
\hline Gestational age at delivery $>\quad 41 \mathrm{WG}$ & $423(14.7)$ & $760(16.1)$ & 0.09 \\
\hline Epidural analgesia & $2723(94.6)$ & $4241(90.1)$ & 0.01 \\
\hline Fetal distress during labor & $1134(39.4)$ & $2034(43.2)$ & 0.01 \\
\hline Occiput posterior position & $63(2.1)$ & $73(1.6)$ & 0.04 \\
\hline Operative vaginal delivery & & & 0.01 \\
\hline Forceps/spatula delivery & $1433(50.2$ & $1265(26.9)$ & \\
\hline Vacuum delivery & $1421(49.8)$ & $3432(73.1)$ & \\
\hline Missing data & 26 & 12 & \\
\hline Birth weight, $g$ & & & 0.01 \\
\hline$<2500$ & $42(1.5)$ & $130(2.8)$ & \\
\hline 2500-3999 & $2553(91.9)$ & $4362(92.9)$ & \\
\hline$>4000$ & $184(6.6)$ & $199(4.2)$ & \\
\hline Missing data & 1 & 18 & \\
\hline Small for gestational age $<10$ th percentile ${ }^{\ddagger}$ & $213(7.4)$ & $500(10.6)$ & 0.01 \\
\hline Hospital characteristics & & & 0.01 \\
\hline Level I maternity unit & $1093(38.0)$ & $693(14.7)$ & \\
\hline Level II maternity unit & $966(33.5)$ & $2202(46.8)$ & \\
\hline Level III maternity unit & $821(28.5)$ & $1814(38.5)$ & \\
\hline
\end{tabular}

WG weeks of gestation. ${ }^{*}$ The 2 groups were compared by the $\mathrm{Chi}^{2}$ tests. ${ }^{\ddagger}$ Growth curves adjusted for gestational age and gender. For each variable, percentages might not sum up to $100 \%$, due to rounding

almost systematically performed in France, as reported by a recent study [38]. Finally, we did not know how the episiotomy was actually performed although its technique is important [39]. To be protective, a mediolateral episiotomy should be at least $45^{\circ}$ from the midline after suturing, which implies a minimum section of $60^{\circ}$ [7]. The French guidelines have recommended this technique since 2005 [40]. However, it is difficult to record the accurate measurement of the incision angle because some discrepancies may exist between the self-reported section angle and the actual angle in current practice [41]. Third, the overall prevalence of OASIs in our study is close to the rate found in a previous cohort study [1]. However, it may be underestimated because ultrasound scans were not routinely used to collect cases of occult OASIs [42]. Fourth, the exclusion of 3 hospitals is likely to have a limited impact because the rates of OASIs and the main risk factors in these hospitals were not significantly different from those in our study. Our results can only be generalized to countries with a moderate 
Table 2 Association between mediolateral episiotomy and OASIs according to the type of operative vaginal delivery

\begin{tabular}{|c|c|c|c|c|c|c|c|}
\hline & \multirow[t]{2}{*}{$\begin{array}{l}\text { Total number } \\
\text { of women }^{\dagger}\end{array}$} & \multicolumn{2}{|c|}{ Mediolateral episiotomy } & \multicolumn{2}{|c|}{$\begin{array}{l}\text { No Mediolateral } \\
\text { episiotomy }\end{array}$} & \multicolumn{2}{|l|}{ RR $(95 \% \mathrm{Cl})$} \\
\hline & & $\begin{array}{l}\text { Number of } \\
\text { women }\end{array}$ & $\begin{array}{l}\text { Number (\%) } \\
\text { with OASIs }\end{array}$ & $\begin{array}{l}\text { Number of } \\
\text { women }\end{array}$ & $\begin{array}{l}\text { Number (\%) } \\
\text { with OASIs }\end{array}$ & Univariate analysis * & Using IPTW* \\
\hline Whole population & 7589 & 2880 & $52(1.8)$ & 4709 & $203(4.3)$ & $0.40(0.29-0.56)$ & $0.33(0.27-0.41)$ \\
\hline Forceps/spatula delivery & 2698 & 1433 & $33(2.3)$ & 1265 & $86(6.8)$ & $0.34(0.22-0.54)$ & $0.38(0.28-0.52)$ \\
\hline Vacuum delivery & 4853 & 1421 & $18(1.3)$ & 3432 & $117(3.4)$ & $0.31(0.18-0.52)$ & $0.27(0.20-0.38)$ \\
\hline
\end{tabular}

$R R$ risk ratio, Cls confidence intervals, IPTW inverse probability of treatment weighting, OASls obstetric anal sphincter injuries. ${ }^{*}$ Mixed model. ${ }^{\dagger}$ Missing data - mode of operative vaginal deliveries: $n=38$. Covariates used to estimate the propensity score: induction of labour, epidural analgesia, occiput posterior position, prolonged pregnancy defined as $>41$ weeks of gestation, fetal distress, type of instruments (forceps/spatula delivery and vacuum delivery), birth weight as a proxy of prenatal suspicion of large for gestational age, year of delivery and level of maternity unit

Table 3 Association between mediolateral episiotomy and the condition of infant at birth ( $\mathrm{pH}$ umbilical artery $<7.10,5$-min Apgar score $<7)$ according to the type of operative vaginal delivery (2013-2017)

\begin{tabular}{|c|c|c|c|c|c|c|c|}
\hline & \multirow[t]{2}{*}{ Total number $^{\dagger}$} & \multicolumn{2}{|c|}{ Mediolateral episiotomy } & \multicolumn{2}{|c|}{ No Mediolateral episiotomy } & \multicolumn{2}{|l|}{$\mathrm{RR}(95 \% \mathrm{Cl})$} \\
\hline & & $n$ & $\begin{array}{l}\text { pH umbilical } \\
\text { artery }<7.10 \\
\text { or 5-min Apgar } \\
\text { score }<7 \text {, } \\
\mathrm{n}(\%)\end{array}$ & $\mathrm{n}$ & $\begin{array}{l}\text { pH umbilical } \\
\text { artery }<7.10 \\
\text { or 5-min Apgar } \\
\text { score }<7 \text {, } \\
\mathrm{n}(\%)\end{array}$ & $\begin{array}{l}\text { Univariate } \\
\text { analysis }\end{array}$ & Using IPTW* \\
\hline Whole population & 3586 & 966 & $55(5.7)$ & 2620 & $245(9.4)$ & $0.73(0.54-1.00)$ & $0.84(0.70-1.01)$ \\
\hline $\begin{array}{l}\text { Forceps/spatula } \\
\text { delivery }\end{array}$ & 1141 & 702 & $20(4.5)$ & 439 & $62(8.8)$ & $0.56(0.32-0.98)$ & $0.56(0.39-0.81)$ \\
\hline Vacuum delivery & 2442 & 526 & $35(6.6)$ & 1916 & $183(9.6)$ & $0.84(0.57-1.23)$ & $0.97(0.79-1.20)$ \\
\hline
\end{tabular}

Table 4 Association between mediolateral episiotomy and the condition of infant at birth ( $\mathrm{pH}$ umbilical artery $<7.10$, 5-min Apgar score $<7$ ) according to the type of operative vaginal delivery and fetal distress status (2013-2017)

\begin{tabular}{|c|c|c|c|c|c|c|c|}
\hline & \multirow[t]{2}{*}{ Total number $^{\dagger}$} & \multicolumn{2}{|c|}{ Mediolateral episiotomy } & \multicolumn{2}{|c|}{ No Mediolateral episiotomy } & \multicolumn{2}{|l|}{ RR $(95 \% \mathrm{Cl})$} \\
\hline & & $n$ & $\begin{array}{l}\text { pH umbilical } \\
\text { artery }<7.10 \\
\text { or 5-min Apgar } \\
\text { score }<7 \text {, } \\
\mathrm{n}(\%)\end{array}$ & $\mathrm{n}$ & $\begin{array}{l}\text { pH umbilical } \\
\text { artery }<7.10 \\
\text { or 5-min Apgar } \\
\text { score }<7 \text {, } \\
\mathrm{n}(\%)\end{array}$ & $\begin{array}{l}\text { Univariate } \\
\text { analysis }^{*}\end{array}$ & Using IPTW* \\
\hline \multicolumn{8}{|c|}{ Forceps/spatula delivery } \\
\hline Fetal distress & 453 & 257 & $7(4.2)$ & 288 & $39(13.5)$ & $0.40(0.16-0.98)$ & $0.52(0.31-0.89)$ \\
\hline No fetal distress & 688 & 274 & $13(3.6)$ & 414 & $23(5.6)$ & $0.80(0.37-1.74)$ & $0.70(0.41-1.20)$ \\
\hline \multicolumn{8}{|l|}{ Vacuum delivery } \\
\hline Fetal distress & 1008 & 228 & $21(9.2)$ & 780 & $112(14.4)$ & $0.83(0.51-1.36)$ & $0.89(0.68-1.17)$ \\
\hline No fetal distress & 1434 & 298 & $14(4.7)$ & 1136 & $71(6.3)$ & $0.81(0.45-1.47)$ & $1.06(0.77-1.48)$ \\
\hline
\end{tabular}

$R R$ risk ratio, Cls confidence intervals, IPTW inverse probability of treatment weighting. ${ }^{*}$ Mixed model after multiple imputation of missing data. ${ }^{\dagger}$ Missing data - mode of operative vaginal deliveries: $n=25$. Covariates used to estimate the propensity score: maternal age, smoking, Body mass index, gestational diabetes, hypertension disorders in pregnancy, induction of labour, epidural analgesia, occiput posterior position, prolonged pregnancy, type of instruments (forceps/ spatula delivery and vacuum delivery), small for gestational age, year of delivery and level of maternity unit

restrictive policy of mediolateral episiotomy and to population with similar characteristics which represents a high-risk subgroup of OASIs. Finally, data on long-term complications are not available but they should be investigated to better inform women who require instrumental assistance to deliver. 
Episiotomy rates for OVD vary across countries [1]. Our rate, which falls within the wide range of figures reported elsewhere, decreased during our study period (from 48 to 23\%). This decrease was also observed in France as a whole [3], and it can be explained by the implementation of the French national obstetrical guidelines [40] and a decrease in the use of forceps/spatula in favor of vacuum, which is associated with lower episiotomy rates.

The protective effect of mediolateral episiotomy in women during OVD remains controversial: several observational studies have shown a lower rate of OASIs when an episiotomy was used, similar to our findings $[10-12,16]$, but other studies found no association [17, 19]. However, the authors of meta-analyses [16, 17] pointed out that the studies used for their analyses had some methodological limitations. To minimize potential indication biases, we used a PS method, similar to Ankarcrona et al. [20]. Compared with their results [20], we observed a greater reduction in the rates of OASIs in women who had an episiotomy compared with those who did not. The rate of episiotomy during vacuum delivery was similar to ours but their rate of OASIs was much higher (13.6\%). No data was reported in forceps delivery.

Another important result of our study is that mediolateral episiotomy was associated with better infant condition after forceps/spatula delivery, and in particular in case of fetal distress. This result is particularly interesting considering that 5-min Apgar scores $<7$ and/or umbilical artery $\mathrm{pH}<7.10$ are known to be associated with adverse neurological outcomes [28-30]. The proportion of fetal distress observed in our study was similar to previous studies $[11,13]$. Fetal distress is recognized as one of the main indications for extraction [43] and may be related to these adverse neonatal outcomes. We hypothesize that the use of episiotomy in cases of fetal distress might reduce the duration of the second stage of labor, potentially improving the infant condition at birth after forceps/spatula delivery. Compared with the vacuum extractor, forceps use is more likely to result in a vaginal birth [43] and the duration tends to be slightly shorter $[34,44]$. Forceps/spatula are used to guide the descending fetus by traction or propulsion, while a vacuum extractor is principally used for cephalic flexion, induction of rotation and comparatively less forceful traction [34]. Consequently, obstetricians can use these two instruments for different indications, which probably explains why we did not observe a significant association between episiotomy and neonatal outcomes in case of vacuum delivery.

Very few studies have investigated the association between episiotomy and neonatal outcomes in forceps deliveries $[13,14]$, and, while they found no association, the proportion of neonatal outcomes was low in these studies, thus limiting the power of their analysis. In addition, their episiotomy rates were much higher than in our study (90 and 53\%, respectively). Consequently, additional studies are needed to confirm these results.

\section{Conclusion}

Using recent prospective data and a propensity score to limit indication biases, we found that the use of mediolateral episiotomy was associated with a lower rate of OASIs in nulliparous women undergoing OVD. We also found that mediolateral episiotomy was associated with favorable infant condition at birth in case of forceps/spatula delivery, particularly in cases of fetal distress, which is one of the main indications for assisted vaginal birth.

Despite the concerns of women and the complications generated by the practice of episiotomy, mediolateral episiotomy may be a means to prevent OASIs during OVD and could improve the condition of the infant at birth after forceps/spatula delivery.

\section{Abbreviations}

BPN: Burgundy Perinatal Network; OASIs: Obstetric anal sphincter injuries; OVD: Operative vaginal deliveries; PSs: Propensity scores.

\section{Supplementary Information}

The online version contains supplementary material available at https://doi. org/10.1186/s12884-022-04396-6.

Additional file 1: Table S1. Change over time in operative vaginal delivery, mediolateral episiotomy practices and OASIs in nulliparous women with operative vaginal delivery at term with live-born singletons. Table S2. Association between mediolateral episiotomy and admission to the neonatal intensive care unit according to the type of operative vaginal delivery (2013-2017).

\section{Acknowledgments}

The authors would like to thank all the maternity hospitals that actively participate in the operations of the Burgundy perinatal network. The authors would like to thank Suzanne Rankin for editing and proofreading the manuscript. Special thanks go to Beatrice Blondel for her very careful reviewing of the paper.

\section{Authors' contributions}

T.D. was involved in study design, analysis and interpretation of the results and drafted the initial manuscript and revised the manuscript. L.M.M., E.D.S. and J.C. were involved in analysis and interpretation of data, and reviewed the manuscript. M. R, D.S., C.Q., E.S. and P.S. were involved in study design, analysis, and interpretation of data, and reviewed the manuscript. All authors approved the final manuscript as submitted and agree to be accountable for all aspects of the work.

\section{Funding}

This research did not receive any specific grant from funding agencies in the public, commercial, or not-for-profit sectors.

\section{Availability of data and materials}

The datasets used and/or analyzed during the current study are available from the corresponding author on reasonable request. 


\section{Declarations}

\section{Ethics approval and consent to participate}

The collection of data by Burgundy Perinatal Network was approved by the French Committee for Data Protection (Commission Nationale Informatique et Liberté - Authorization number 455451) and this study was conducted in accordance with the Declaration of Helsinki. The database was used in accordance with article 6-1-c (Lawfulness of processing) of the European General Data Protection Regulation. Consent to participate was not required by law due to the retrospective and non-interventional nature of the study (https:// www.legifrance.gouv.fr/jorf/id/JORFTEXT000037187443).

Ethics committee approval was not required for this study because we solely reported on anonymized data from patient medical records. These data have been collected in accordance with our usual practices and patients underwent no supplementary procedures for this investigation. Upon admission, each patient at our institution receives a written document that specifically mentions the possibility that anonymized medical data collected during hospitalization could be used for medical research.

\section{Consent for publication}

Not applicable.

\section{Competing interests}

Author Paul Sagot received funding from the following commercial companies: Merck Serono, Ferring, MSD France SAS, Teva Sante SAS, Gedeon Richter France, Effik S. A, and GE Medical Systems SCS. The author confirms that none of this funding was used to support the research in this study. The other authors report no conflict of interest.

\section{Author details}

'Dijon University Hospital, Burgundy Perinatal Network, Pôle de GynécologieObstétrique, Médecine Fœtale et Stérilité Conjugale, F-21000 Dijon, France. ${ }^{2}$ Obstetrical, Perinatal and Pediatric Epidemiology Team (EPOPé), Center of Research in Epidemiology and Statistics (U1153), Team EPOPé U1153, Université de Paris, Inserm, Paris, France. ${ }^{3}$ Dijon University Hospital, Service de Biostatistique et d'Informatique Médicale (DIM), F-21000 Dijon, France. ${ }^{4}$ Inserm, CIC 1432, Clinical Epidemiology Unit, Dijon, France. ${ }^{5}$ Dijon University Hospital, Clinical Investigation Center, Clinical Epidemiology Unit, Dijon, France. ${ }^{6}$ Dijon University Hospital, Pôle de Pédiatrie, F-21000 Dijon, France. ${ }^{7}$ Université ParisSaclay, UVSQ, Univ. Paris-Sud, Inserm, High-Dimensional Biostatistics for Drug Safety and Genomics, CESP, Villejuif, France.

\section{Received: 24 August 2021 Accepted: 11 January 2022}

\section{Published online: 19 January 2022}

\section{References}

1. Blondel B, Alexander S, Bjarnadottir RI, Gissler M, Langhoff-Roos J, NovakAntolic $Z$, et al. Variations in rates of severe perineal tears and episiotomies in 20 European countries: a study based on routine national data in euro-Peristat project. Acta Obstet Gynecol Scand. 2016;95(7):746-54.

2. Mous M, Muller SA, de Leeuw JW. Long-term effects of anal sphincter rupture during vaginal delivery: faecal incontinence and sexual complaints. BJOG. 2008;115(2):234-8.

3. Blondel B, Coulm B, Bonnet C, Goffinet F, Le Ray C. National Coordination Group of the National Perinatal S. trends in perinatal health in metropolitan France from 1995 to 2016: results from the French National Perinatal Surveys. J Gynecol Obstet Hum Reprod. 2017:46(10):701-13.

4. Pergialiotis V, Vlachos D, Protopapas A, Pappa K, Vlachos G. Risk factors for severe perineal lacerations during childbirth. Int J Gynaecol Obstet. 2014;125(1):6-14

5. Desplanches T, Szczepanski E, Cottenet J, Semama D, Quantin C, Sagot P. A novel classification for evaluating episiotomy practices: application to the Burgundy perinatal network. BMC Pregnancy Childbirth. 2019;19(1):300.

6. Ducarme G, Pizzoferrato AC, de Tayrac R, Schantz C, Thubert T, Le Ray C, et al. Perineal prevention and protection in obstetrics: CNGOF clinical practice guidelines. J Gynecol Obstet Hum Reprod. 2018.
7. Royal College of Obstetrians and Gynecologists (RCOG). The management of Third and Fourth Degree Perineal Tears. Green-top Guideline 2015:29:2.

8. American College Obstetrians and Gynecologists. Practice Bulletin No. 198 summary: prevention and Management of Obstetric Lacerations at vaginal delivery. Obstet Gynecol 2018;132(3):795-797.

9. Murphy DJ, Macleod M, Bahl R, Goyder K, Howarth L, Strachan B. A randomised controlled trial of routine versus restrictive use of episiotomy at operative vaginal delivery: a multicentre pilot study. BJOG. 2008;115(13):1695-702 discussion 702-3.

10. de Leeuw JW, de Wit C, Kuijken JP, Bruinse HW. Mediolateral episiotomy reduces the risk for anal sphincter injury during operative vaginal delivery. BJOG. 2008;115(1):104-8.

11. van Bavel J, Hukkelhoven C, de Vries C, Papatsonis DNM, de Vogel J, Roovers JWR, et al. The effectiveness of mediolateral episiotomy in preventing obstetric anal sphincter injuries during operative vaginal delivery: a ten-year analysis of a national registry. Int Urogynecol J. 2018;29(3):407-13.

12. Muraca GM, Liu S, Sabr Y, Lisonkova S, Skoll A, Brant R, et al. Episiotomy use among vaginal deliveries and the association with anal sphincter injury: a population-based retrospective cohort study. CMAJ. 2019;191(42):E1149-E58.

13. Macleod M, Strachan B, Bahl R, Howarth L, Goyder K, Van de Venne M, et al. A prospective cohort study of maternal and neonatal morbidity in relation to use of episiotomy at operative vaginal delivery. BJOG. 2008;115(13):1688-94.

14. Youssef R, Ramalingam U, Macleod M, Murphy DJ. Cohort study of maternal and neonatal morbidity in relation to use of episiotomy at instrumental vaginal delivery. BJOG. 2005;112(7):941-5.

15. de Vogel J, van der Leeuw-van Beek A, Gietelink D, Vujkovic M, de Leeuw $\mathrm{JW}$, van Bavel J, et al. The effect of a mediolateral episiotomy during operative vaginal delivery on the risk of developing obstetrical anal sphincter injuries. Am J Obstet Gynecol. 2012;206(5):404 e1-5.

16. Lund NS, Persson LK, Jango H, Gommesen D, Westergaard HB. Episiotomy in vacuum-assisted delivery affects the risk of obstetric anal sphincter injury: a systematic review and meta-analysis. Eur J Obstet Gynecol Reprod Biol. 2016;207:193-9.

17. Sagi-Dain L, Sagi S. Morbidity associated with episiotomy in vacuum delivery: a systematic review and meta-analysis. BJOG. 2015:122(8):1073-81.

18. Raisanen S, Vehvilainen-Julkunen K, Cartwright R, Gissler M, Heinonen S. Vacuum-assisted deliveries and the risk of obstetric anal sphincter injuries-a retrospective register-based study in Finland. BJOG. 2012;119(11):1370-8.

19. Ampt AJ, Ford JB, Roberts CL, Morris JM. Trends in obstetric anal sphincter injuries and associated risk factors for vaginal singleton term births in New South Wales 2001-2009. Aust N Z J Obstet Gynaecol. 2013;53(1):9-16.

20. Ankarcrona V, Zhao H, Jacobsson B, Brismar WS. Obstetric anal sphincter injury after episiotomy in vacuum extraction: an epidemiological study using an emulated randomised trial approach. BJOG. 2021.

21. Gachon B, Fradet Menard C, Pierre F, Fritel X. Does the implementation of a restrictive episiotomy policy for operative deliveries increase the risk of obstetric anal sphincter injury? Arch Gynecol Obstet. 2019;300(1):87-94.

22. Austin PC, Stuart EA. Moving towards best practice when using inverse probability of treatment weighting (IPTW) using the propensity score to estimate causal treatment effects in observational studies. Stat Med. 2015;34(28):3661-79.

23. D'Agostino RB Jr. Propensity score methods for bias reduction in the comparison of a treatment to a non-randomized control group. Stat Med. 1998;17(19):2265-81.

24. Murphy DJ, Liebling RE, Verity L, Swingler R, Patel R. Early maternal and neonatal morbidity associated with operative delivery in second stage of labour: a cohort study. Lancet. 2001;358(9289):1203-7.

25. Fodstad K, Staff AC, Laine K. Episiotomy preferences, indication, and classification--a survey among Nordic doctors. Acta Obstet Gynecol Scand. 2016;95(5):587-95.

26. Sagi-Dain L, Sagi S. Indications for episiotomy performance - a crosssectional survey and review of the literature. J Obstet Gynaecol. 2016:36(3):361-5. 
27. Quantin C, Gouyon B, Avillach P, Ferdynus C, Sagot P, Gouyon JB. Using discharge abstracts to evaluate a regional perinatal network: assessment of the linkage procedure of anonymous data. Int J Telemed Appl. 2009;2009:181842.

28. Ehrenstein V, Pedersen L, Grijota M, Nielsen GL, Rothman KJ, Sorensen HT. Association of Apgar score at five minutes with long-term neurologic disability and cognitive function in a prevalence study of Danish conscripts. BMC Pregnancy Childbirth. 2009;9:14.

29. Yeh P, Emary K, Impey L. The relationship between umbilical cord arterial $\mathrm{pH}$ and serious adverse neonatal outcome: analysis of 51,519 consecutive validated samples. BJOG. 2012;119(7):824-31.

30. Malin GL, Morris RK, Khan KS. Strength of association between umbilical cord $\mathrm{pH}$ and perinatal and long term outcomes: systematic review and meta-analysis. BMJ. 2010;340:c1471.

31. Austin PC. An introduction to propensity score methods for reducing the effects of confounding in observational studies. Multivariate Behav Res. 2011;46(3):399-424.

32. Parer JT, Livingston EG. What is fetal distress? Am J Obstet Gynecol. 1990;162(6):1421-5 discussion 5-7.

33. Ferdynus C, Quantin C, Abrahamowicz M, Burguet A, Sagot P, Gouyon JB. Comparison of the ability of alternative birthweight and fetal weight standards to identify preterm newborns at increased risk of perinatal death. BJOG. 2013;120(12):1456-64.

34. Vayssiere C, Beucher G, Dupuis O, Feraud O, Simon-Toulza C, Sentilhes L, et al. Instrumental delivery: clinical practice guidelines from the French College of Gynaecologists and Obstetricians. Eur J Obstet Gynecol Reprod Biol. 2011;159(1):43-8.

35. Rubin DB, Schenker N. Multiple imputation in health-care databases: an overview and some applications. Stat Med. 1991;10(4):585-98.

36. The National Institute of Statistics and Economic Studies - INSEE. Les Naissances en 2018. (Available online https://www.insee.fr/fr/statistiques/ 4190314? sommaire $=4190525$ ).

37. Hals E, Oian P, Pirhonen T, Gissler M, Hjelle S, Nilsen EB, et al. A multicenter interventional program to reduce the incidence of anal sphincter tears. Obstet Gynecol. 2010;116(4):901-8.

38. Riethmuller $D$, Ramanah R, Mottet N. Fetal expulsion: which interventions for perineal prevention? CNGOF perineal prevention and protection in obstetrics guidelines. Gynecol Obstet Fertil Senol. 2018;46(12):937-47.

39. Stedenfeldt M, Pirhonen J, Blix E, Wilsgaard T, Vonen B, Oian P. Episiotomy characteristics and risks for obstetric anal sphincter injuries: a case-control study. BJOG. 2012;119(6):724-30.

40. College National Gynécologues Obstétriciens Français. Episiotomy: recommendations of the CNGOF for clinical practice (December 2005). Gynecol Obstet Fertil. 2006;34(3):275-27.

41. Bechard F, Geronimi J, Vieille P, Letouzey V, de Tayrac R. Are we performing episiotomies correctly? A study to evaluate French technique in a highrisk maternity unit. J Gynecol Obstet Hum Reprod. 2018;47(7):331-8.

42. Hickman LC, Propst K. Accurate diagnosis and repair of obstetric anal sphincter injuries: why and how. Am J Obstet Gynecol. 2020;222(6):580 e1-5.

43. O'Mahony F, Hofmeyr GJ, Menon V. Choice of instruments for assisted vaginal delivery. Cochrane Database Syst Rev. 2010;11:CD005455.

44. Black M, Murphy DJ. Forceps delivery for non-rotational and rotational operative vaginal delivery. Best Pract Res Clin Obstet Gynaecol. 2019;56:55-68.

\section{Publisher's Note}

Springer Nature remains neutral with regard to jurisdictional claims in published maps and institutional affiliations.

Ready to submit your research? Choose BMC and benefit from:

- fast, convenient online submission

- thorough peer review by experienced researchers in your field

- rapid publication on acceptance

- support for research data, including large and complex data types

- gold Open Access which fosters wider collaboration and increased citations

- maximum visibility for your research: over 100M website views per year

At BMC, research is always in progress.

Learn more biomedcentral.com/submissions 